\title{
The Art of Astrological Computations: Conrad Heingarter and the Manuscript Paris, BnF latin 7295A
}

\begin{abstract}
Late medieval astronomical manuscripts produced in Europe attest to different kinds of historical practices. Computations are one such practice and the focus of this contribution. My hypothesis is that a detailed analysis of the manuscripts and a deep understanding of what computation was for late medieval astrologers or astronomers in Europe are mutually beneficial. By concentrating on one of the manuscripts associated with the late fifteen-century astrologer Conrad Heingarter, I show that the document has specific characteristics of a slowly assembled personal toolbox for computation. I also argue that the multigraphic properties of the document are fundamental to understanding calculations that values comparing multiple computation paths among astronomical quantities.
\end{abstract}

\section{Introduction}

The manuscript evidence on which historians of late medieval astronomy in Europe rely was essentially shaped by the historical actors who used those manuscripts in scientific practices. These documents are contemporaneous to the practices they attest. ${ }^{1}$ In some cases, it is even possible to examine autograph manuscripts of important astronomers and astrologers of the period. ${ }^{2}$ Some of the practices attested by these sources may be closely linked to the actual production of manuscripts (e.g., when astronomical material is adapted to a specific dedicatee or when a student copies a manuscript in order to learn astronomy); other practices relate to the use of manuscripts to achieve specific tasks such as computation. In this contribution, I want to investigate this second kind of practice. My hypothesis is that a progressive unravelling of the complexity of manuscripts will allow a deeper and more contextualised understanding of what computation, understood as a form of mathematical reasoning, was for late

1 See, for instance, the list of manuscripts in Chabás 2019, 413-423; or the manuscript descriptions in Pedersen 2002, 87-214.

2 Husson and Saby 2019, 205-234.

2 Open Access. (C) 2021 Matthieu Husson, published by De Gruyter. (c) BY-NC-ND This work is licensed under the Creative Commons Attribution-NonCommercial-NoDerivatives 4.0 International License. 
medieval astrologers or astronomers in Europe. Reciprocally, the analysis of these manuscripts' material, graphical, and intellectual features and of their interactions will be enlightened by an increasing comprehension of the computations.

About a dozen manuscripts are now identified as having been, in the second half of the fifteenth century, part of a collection assembled by Conrad Heingarter. ${ }^{3}$ Conrad Heingarter's manuscripts can be identified because he annotated, or in some cases even copied, parts of them himself. ${ }^{4}$ Together, these manuscripts form an exceptional archive from which much can be learned about Heingarter's biography. ${ }^{5}$ Born in Horgen by Lake Zürich, he studied arts and medicine in Paris between the early 1450's (licence in arts, 1454) and 1466 (master in medicine). He was an astrologer and physician in the service of Jean II de Bourbon and his wife, Jeanne de France (sister of Louis XI), from 1464 onward. He also served as a physician and ambassador to King Louis XI and maybe to his successor Charles VIII. Most of Heingarter's manuscripts relate to his practice as a physician and astrologer. He authored commentaries on Ptolemy's Tetrabiblos and Ps.-Ptolemy's Centiloquium. ${ }^{6}$ He also wrote several treatises mixing dietary recommendations and astrological considerations. ${ }^{7}$ Beside astrology and medicine, four Heingarter manuscripts contain material dealing with mathematical astronomy. ${ }^{8}$ Among them, Paris, Bibliothèque nationale de France, latin 7295A can be described as a 'toolbox' manuscript dedicated to astronomical computations. ${ }^{9}$ This manuscript, one among many similar manuscripts produced in Europe during the fourteenth and fifteen centuries, is the subject of this article. ${ }^{10}$

Heingarter copied between half and two thirds of the manuscript. ${ }^{11}$ The annotations, rubrication, and punctuation introduced by Heingarter in the

3 Paris, BnF, lat. 7197, 7273, 7295A, 7305, 7314, 7333, 7347, 7432, 7446, 7450, and 11232.

4 Many of these 'Heingarter manuscripts' were already identified about a century ago by Lynn Thorndike, who devotes two chapters to Heingarter in his History of Magical and Experimental Sciences (Thorndike 1934, 357-385). Thorndike describes Heingarter as an 'astrologer' and a 'physician'. Here I consider Heingarter's astronomical computation practices.

5 Nicoud 2007, <doi.org/10.4000/books.efr.1448>; Jacquart 1979, 57.

6 The Tetrabiblos with an original commentary from Heingarter is found in Paris, BnF, lat. 7305. The Centiloquium and the Tetrabiblos in Paris, BnF, lat. 7432.

7 Paris, BnF, lat. 7446 and 11232.

8 Husson 2019, 247-274.

9 Kremer 2021.

10 A high-resolution colour digitalisation of the manuscript can be consulted at <gallica.bnf.fr/ ark:/12148/btv1b10027322j> (accessed in Jan. 2021).

11 Heingarter copied the main text on fols $1^{\mathrm{r}}-32^{\mathrm{r}}, 35^{\mathrm{r}}-45^{\mathrm{r}}, 49^{\mathrm{r}}-93^{\mathrm{r}}, 145^{\mathrm{r}}-142^{\mathrm{r}}, 179^{\mathrm{v}}-193^{\mathrm{v}}$. Heingarter annotated, for instance, fols $99^{\mathrm{r}}, 100^{\mathrm{r}}, 164^{\mathrm{r}}$. 
manuscript are interesting but of secondary importance for our purpose. Such features have a local interest for specific astronomical topics, but they do not disclose the structure of the computation. Therefore, it is by describing the manuscript itself that I propose to grasp the kind of computation practices that Heingarter envisioned when composing this manuscript. I will thus focus in turn on the manuscript's material and graphical features as well as its content.

\section{Material aspects: A composite manuscript}

The manuscript binding is modern (Lefebvre 1828)..$^{12}$ It gathers 193 folios in 17 paper quires of various sizes $\left(2^{12} ; 1^{10} ; 1^{6} ; 1^{8} ; 1^{12} ; 1^{14} ; 2^{12} ; 1^{16} ; 1^{13} ; 1^{12} ; 1^{5} ; 1^{10} ; 1^{12} ; 1^{14} ; 1^{13}\right)$. On two occasions, folios are glued: fol. 115 is glued so that a quire of 14 folios is turned into one of 13 folios; fol. 139 is glued so that a quire of 4 folios is turned into one of 5 folios. These features show that the manuscript was not composed with a great deal of attention to the uniformity of its material structure. Rather these features indicate a collection of various elements produced on different occasions by different means. Such features are quite characteristic of toolbox manuscripts, which are often 'opportunistic', and content-oriented rather than the result of a carefully planned production process that is attentive to the physical harmony of the codex.

Six different watermarks are present in the manuscript. ${ }^{13}$ Four of them point to paper produced in Paris between 1451 and 1461. The two other watermarks point to Chateaudun 1463 and Pont-à-Mousson 1459. The distribution of the various types of paper in the different quires does not exhibit any clear pattern. This fact again indicates that the manuscript itself was composed with no particular attention to uniformity in material used. The different quires of this manuscript were probably copied in Paris during the latter part of Heingarter's stay at the university while he was mostly a student in medicine and beginning in the service of Jean II de Bourbon. This chronological indication is important: when he composed this manuscript, Heingarter was for the most part already a trained astronomer, at least on the basic topics. ${ }^{14}$

12 See the online catalogue notice by Laure Rioust (2018) at <archivesetmanuscrits.bnf.fr/ ark:/12148/cc664943> (accessed in Jan. 2021).

13 Briquet 1548 on fols 10, 26, 34; Briquet 9167 on fol. 47; Briquet 1527 on fols 50, 55; Briquet 1683-1684 on fols 64, 67, 181; Briquet 15067 on fols 76, 79, 95; Briquet 11475 on fols 100, 127.

14 Heingarter learned liberal arts and more specifically astronomy in Paris (see Paris, BnF, lat. 7197). 
A small flyleaf is added between fols 131-132 and 135-136 isolating a subset of a larger 12-folio quire. This feature suggests that the different quires of the manuscript had a life prior to being bound. This insight is reinforced by a supplementary observation. The last two folios of the third, fifth, ninth and fourteenth quires are left blank. In each of these four cases, the last blank page and the following one from the next quire exhibit traces of use that seem to indicate independent circulation as a booklet before binding. This life before binding is also characteristic of toolbox manuscripts. Such manuscripts were likely to exist in a pre-codex format, allowing for different ordering of the quires and booklets, easier simultaneous consultation of different parts of the manuscript and a process of slow accumulation and selection of different elements. In order to understand how the manuscript can be used in astronomical computations, it is very important to keep in mind that the physical configuration of the manuscript was, in its early stages, in a pre-codex, pre-binding form. This recognition has at least two consequences. First, the current ordering of the different booklets in the manuscript must be relativized even though, when the booklets were assembled in a codex, a specific ordering was chosen. Second, before binding, it would have been possible to open several of these booklets simultaneously in front of a reader.

\section{Visual aspects: A multigraphic manuscript}

The main visual feature of the manuscript, shared by most contemporaneous European astronomical manuscripts, is its use of three different types of contents: texts, numerical tables, and diagrams (Fig. 1). Diagrams and tables have specific kinds of paratexts such as table headings or textual-diagram labels. The paratexts are an important unifying element between the three kinds of contents. These texts, tables, and diagrams are the working tools with which one computes astronomical phenomenon. Their distribution in the manuscript reveals core features of the computation practices that were supported by this document. I describe first this distribution and then each of the elements in turn.

The codex comprises 386 pages, 35 of which are blank (Fig. 2). There are 190 pages inscribed with text, 173 pages inscribed with tables, and 58 pages inscribed with diagrams. Only 3 pages are inscribed with all three types of graphical elements, while 14 pages have both text and tables (i.e. a little under 10 per cent of the tables are found with text), and 51 have text and diagrams (i.e. around 90 per cent of the diagrams are found with text). In this manuscript, 
there is no instance of diagrams and tables on the same page without text. However, diagrams are found alone on 6 pages while text is found alone 124 times and tables 156 times. The first two booklets of the codex comprise 125 pages with text, 58 with tables, and 46 with diagrams. The last four booklets of the codex comprise 115 pages with tables, 65 with text, and 12 with diagrams. Thus, there is also a general distribution of these elements in the codex: texts usually come first, while tables come after.

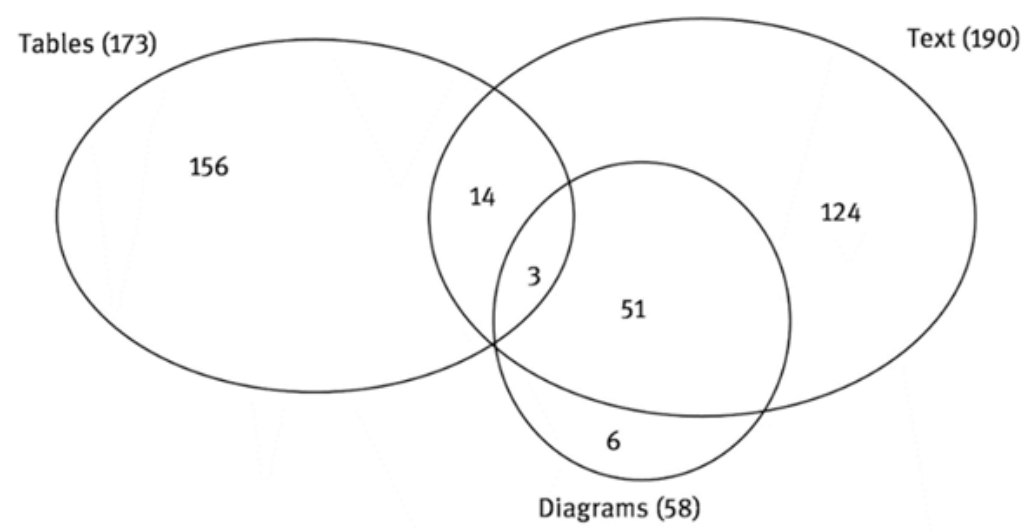

Fig. 2: Combination of text, tables, and diagrams in the pages of the manuscript.

Tables and text share almost an equal portion of the pages in the document, but tables are, by far, the most autonomous element. Diagrams are in most cases dependent on text. In between these two extremes, text is complemented by diagrams or tables on about a third of the pages where text is inscribed. Finally, tables and diagrams seem to require text in order to be combined on the same page: a direct confrontation of both elements does not seem to have been easily meaningful for late medieval astronomers.

The layout of text in the manuscript is that of the late medieval European manuscript cultures to which the codex belongs. From folio 1 to 98 , the pages are mostly organised in one large column. In this first section, comprising the first two booklets, the ruling alternates between around 42 lines (first booklet) and around 45 lines (second booklet). These first two booklets are also unified by some text-structuring decorative elements: a hierarchy of illuminated fifteenth-century Parisian-style letters (four red and blue illuminated letters in the first booklet, one red and brown in the second booklet); alternate red and blue capital letters (not all of them realised; see fols $2^{\mathrm{r}}-8^{\mathrm{v}}, 35^{\mathrm{r}}-45^{\mathrm{r}}, 49^{\mathrm{r}}-62^{\mathrm{r}}$ ); and 
alternate red and blue pieds de mouche. These first two booklets are also copied in Heingarter's hand. From folio 99 to the end, the page layout is in two columns (the only exception is fol. $181^{\mathrm{v}}$ ). The ruling is mostly of 45 lines, but sections of 50 lines (fols 182-193) or even 62 lines (fols 174-181) do occur. The structuring of the text by means of decorative elements is also more diverse and generally less polished in these last four booklets of the manuscript. Illuminated letters are absent. Two different styles of red capital letters are used in two different sections (fols $115^{\mathrm{r}}-144^{\mathrm{v}}$ and $174^{\mathrm{r}}-180^{\mathrm{v}}$, respectively). Black and red pieds de mouche are used in various places (mostly fols $101^{\mathrm{r}}-111^{\mathrm{v}}, 174^{\mathrm{r}}-180^{\mathrm{v}}$ ), along with more refined punctuation marks (virgulae). Among the eight quires of this second part, Heingarter copied only two (quire 14 and quire 17). Intervention by Heingarter is nevertheless apparent in each of these quires via marginalia of different types, including several manicula. These elements strongly imply that Heingarter copied the first half of the manuscript. In the second part of the manuscript, Heingarter's interventions are those of a compiler and attentive reader (adding, for instance, rubrication and punctuation), except for two quires. Qualitatively, the first half of the codex, copied by Heingarter, mostly contains text, while the second half, mainly collected and read but not copied by Heingarter, mostly contains tables. The document thus attests a situation where texts and tables share a balanced amount of page space but exhibit different levels of engagement by Heingarter. He interacts more intimately with texts that he mostly copied himself, as opposed to the tables for which Heingarter mostly trusted other copyists.

In a discussion of the visual aspects and distribution of numerical tables in the manuscript, it is important to introduce a distinction. I use the word 'grid' to refer to a particular ruling of the page that displays lines and columns. A grid can be used for many different purposes on a page, one of which is to display numerical tables. 'Numerical tables' are mathematical objects defined by a series of relations between argument and entries. Numerical tables can be displayed in different ways, via prose, within different kinds of graphs and diagrams, or within grids. To some extent, the visual features of a grid share the properties of other kinds of non-discursive diagrammatic representations in numerical tables.

When tables are displayed along with text or diagrams on the same page, the grid used is simple and of small dimensions (Fig. 1). Such grids are often used to display numerical information in relation to a diagram (e.g. fols $16^{\mathrm{r}}$ and $30^{\mathrm{r}}$ ). Most of the 14 small grids found on pages with text only are also directly related to a diagram found on the previous or following page of the manuscript. These small grids can be considered direct paratexts to the diagrams or an ex- 
tension of their labelling system. In one instance, on fol. $182^{v}$, the relation between the diagram and the table is inverted: the diagram is used to display in a geometrical way the relations displayed in the tables. Small grids sharing the page with text are also used to display other kinds of tables that provide information about the mean motions of celestial objects (e.g. fols $38^{\mathrm{v}}, 39^{\mathrm{r}}, 40^{\mathrm{r}}$, $40^{v}$ ). The meaning of these tables is not directly dependent on a diagram or a text. Grids for these kinds of tables tend to be a little larger than the first kind. They can be also a little more complex, since one grid, for instance, can be used to display two different tables concomitantly sharing their argument column (e.g. fols $40^{\mathrm{r}}$ or $40^{\mathrm{v}}$ ).

In this respect, these small grids share some features of the larger series of grids filling most of the second half of the manuscript (see Fig. 3). These larger grids often fill the full space of the page, though in some cases with comfortable marginal areas (up to about a third of the page, on fol. $120^{\mathrm{r}}$ for instance). On the other hand, a given page can have more than one grid. The most frequent situation is to have two grids on one page, but three grids are not rare and fol. $116^{\mathrm{r}}$, for instance, has four grids. Each of these grids can be quite complex and display more than one numerical table. The numerical tables displayed in these grids are often long and require several grids on several pages for their presentation. In many cases red and black ink are used in order to enhance readability and distinguish different tables in a given grid, or the arguments from the entries, or the heading of the tables from their values, etc. (e.g fol. 120 $)$. Finally, graphical aspects also include broken lines cutting across the grid. These lines are embedded with different meanings. For instance, in Fig. 3 such broken lines dividing the grid can be seen. They mark a separation between meridional and septentrional values of the latitude of Mercury (i.e. to some extent, this line is a projection onto the grid of the celestial ecliptic).

Grids of numerical tables are a fundamental tool for astronomical computations. Their visual characteristics and distribution in the manuscript reflect the complexity and intended precision of these computations. Grids running for multiple pages allow the display of a large amount of numerical information in long and precise numerical tables. Moreover, these tables often share the same series of grids, indicating that astronomical computations require the concomitant consideration of sets of relations between astronomical quantities rather than a more pedestrian path going successively from one relation to the next. These large and complex tables are the majority, but smaller tables appearing in simpler grids related to diagrams through text are also important as they illustrate the intervention of numerical tables in a different context, less 'frontline' with respect to computation. 
In many ways, diagrams are distributed in the codex along the same patterns as these small numerical tables in simple grids. About 30 per cent of these diagrams appear in connection with one of these small tables on the same, previous, or following page. About 60 per cent of the diagrams appear in a textual context but are not associated with any tables. The last 10 per cent are diagrams filling an entire page. A portion of them appear on their own (Fig. 4), independently of any direct relation to a text (or a table). These cases indicate that diagrams possess an autonomy and can generate meaning on their own.

Diagrams in the manuscript all rely on a very simple repertoire of geometric shapes involving circles and straight lines. However, they can be distinguished according to some of their visual properties, especially with respect to the way they use different kinds of lettered, textual, or numerical/graduation labels (Fig. 5). Diagrams using lettered labels are the majority, with 51 cases. Textual labels (i.e. nouns or nominal groups mostly) are present as well in 43 cases. Graduations and/or numbers labels appear in 31 cases. Graduation and numbers never appear alone as labels. They are always coupled with at least one other kind of label. Texts are also quite rare as a stand-alone label for a diagram, only 3 cases. Letters, on the other hand, are the only label in 15 cases. The combination of text and letters is the most frequent type of label with 10 cases. Text and graduations/numbers are attested in 5 cases. The combination of graduations/numbers with letters is very rare, only 1 case. ${ }^{15}$ There are 25 diagrams combining the three kinds of labels.

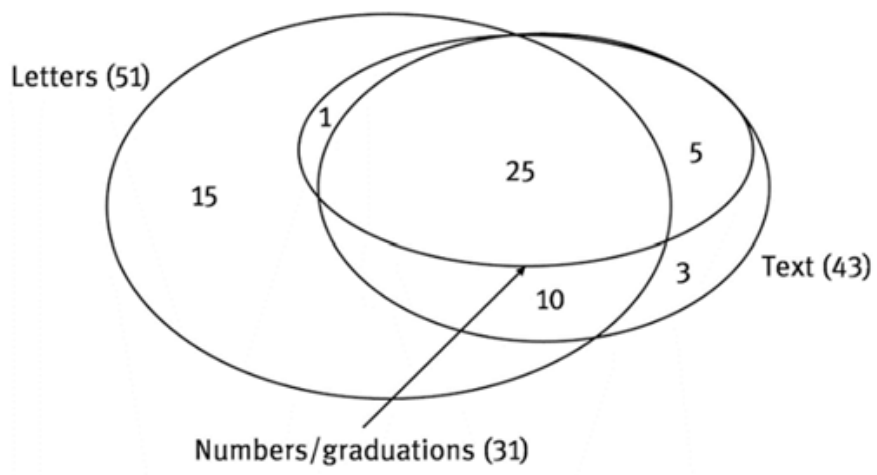

Fig. 5: Repartition of types of diagram's labels.

15 This is the specific situation of fol. $182^{\mathrm{v}}$, mentioned above in relation to a small grid of numerical tables. 
Lettered diagrams are the majority. Actually, direct mentions of Euclid's Elements in relation to some of these diagrams are rare but not absent from the manuscript. In most cases, however, lettered diagrams are supplemented either with textual labels or with graduation and numbers. Small tables are also used in some cases to complement the lettered labels. Thus, lettered labels must be used in different ways than in the Elements. Moreover lettered labels were not sufficient to cover a range of uses that appears to be much broader for diagrams. It is interesting, for instance, with respect to the relation of diagrams to quantification, that graduations/numbers labels require the presence of at least one other kind of label (in 80 per cent of the cases in fact, graduations/numbers labels appear with lettered and textual labels).

Other visual features of astronomical diagrams in the manuscripts, although they are more difficult to quantify, are of importance. Some diagrams (e.g. fol. 183 ${ }^{\mathrm{v}}$ ) seem purely mathematical. None of their elements represents, even indirectly, an astronomical quantity. The geometrical reasoning expounded in this part of the manuscript relies on a series of 3 diagrams (all to be found on fol. $183^{v}$ ). Diagrams, like tables, can be organised in series. On the other hand, a cosmological diagram such as that of fol. $191^{\mathrm{v}}$ represents some aspects of solar eclipses with moon shadow coloured in black ink. Like the mathematical diagrams of fol. $183^{\mathrm{v}}$, the eclipse diagram of fol. $191^{\mathrm{v}}$ initiates a broader series of 4 diagrams that are to be found in the following folios. These diagrams display relations between astronomical quantities by representing directly astronomical objects (here the sun and the moon). Obviously, these two kinds of diagrams rely on quite different modes of representation. Instrument diagrams (e.g. fol. $50^{\mathrm{r}-\mathrm{v}}$ ) are yet another kind of diagram with quite distinctive features. They appear in series, which shows the 'construction' process of the instruments or different details of the object. These diagrams represent, through an instrument, specific relations between astronomical quantities. Such diagrams do rely in some cases on a direct representation of astronomical objects (notably the stars on the rete of the astrolabe) but this is not systematic. Some of these instrument diagrams are even metrically exact, and thus can be used as 'paper' instruments for some kinds of computational use. Theorica planetarum diagrams are yet another way to display sets of relations between astronomical quantities. They are often much closer to the representation chosen by numerical tables. For instance, they provide geometrical representation of interpolation coefficients (minuta proportionalia) which are typical artefacts of numerical tables' computation practices (Fig. 4). 
The manuscript has several instances of variations among versions of the 'same' diagram. ${ }^{16}$ Some of these instances (Fig. 4) are part of a stand-alone series of diagrams that are meaningful on their own, independent of any direct relation to text or tables, while others diagrams are inserted into a text. These possibilities are grounded in the fact that these diagrams, like most of the diagrams in the manuscript, are found in many other manuscripts. They are elements of a shared epistemic visual culture in mathematical astronomy where meaning is likely to arise even from these small variations.

In spite of the fact that they rely on a very simple geometrical repertoire of shapes, diagrams appear to have a broad visual range, including a complex use of different kinds of labels and different modes of representation for the relationship between astronomical quantities. Like grids for numerical tables, diagrams generally show sets of relations between astronomical quantities rather than each relation one by one. Different types of diagrams, with respect to their labelling systems and their modes of representation, will generally also select different sets of relations between astronomical quantities. Like grids for numerical tables, diagrams are organised in series that can display different kinds of processes or analysis. Finally, variations on 'same' diagrams provide slightly different representations of identical sets of relations between astronomical quantities. Thus, together diagrams produce a robust and nuanced set of tools for identifying and analysing pertinent astronomical quantities and their relations in the study of celestial phenomenon. Diagrams, and more generally geometrical insights, have a thick and diverse role in the mathematical practice attested by this manuscript.

Inspection of the manuscript's visual aspects confirms that Heingarter was deeply engaged with the manuscript. This engagement is different with respect to text and tables. Moreover, analysing the visual organisation of diagrams and grids of numerical tables provides important information about the nature of the computations supported by the manuscript. Consideration of the various sets of mathematical relations between astronomical quantities, presented in diagrams or in grids of numerical tables, is at the centre of this mathematical practice. It is also important to remember that these two types of graphical expressions for sets of relationships between astronomical quantities can appear together on a page only if they are supplemented by a text. Indeed diagrams and tables share a common terminology used in table headings and in diagram labels. Thus, it is likely that various texts and more deeply a specific subset of

16 Compare Fig. 4 with fol. $188^{\text {r }}$, both connected with Mercury. 
expressions shared by the different graphical modes used in the manuscript have a central role in articulating the computation.

\section{Intellectual aspects: A multiple-text manuscript}

Twenty-three works can be identified in the manuscript. Ten of them cover 307 pages, about 90 per cent of the inscribed pages of the codex. On the other hand, the remaining 13 works share only 44 pages, that is, a little more than 12 per cent of the inscribed pages. A few works, which constitute the core of the manuscript, are copied down in full. These core works are accompanied by about the same number of shorter works, to which very little space is devoted. These smaller pieces are often fragments of larger works (only a portion of a larger work is copied, or several portions are compiled, or the original work is abridged by other means). The shorter pieces can also be complete and independent but nevertheless small works. It is often very difficult to identify these fragments and short works because parts of unedited works are almost impossible to detect, especially if the wording, in case of a text, has been slightly adapted or variant. While difficult to identify, these fragments and short works indicate the type of complementary and auxiliary material that Heingarter felt was necessary to handle the larger texts. Thus, the relationship between the core works and the fragments or short works is an important aspect of the astronomical computations attested by the manuscript.

The first booklet (quires 1 to 5) is a perfect illustration of this situation. It contains four works. The first one is Campanus de Novara's Theorica planetarum. ${ }^{17}$ It takes up 64 pages (fols $1^{\mathrm{r}}-32^{\mathrm{v}}$ ) with an intricate combination of text, diagrams, and tables. The text describes planetary models qualitatively in their geometrical and cosmological dimensions. It also proposes an instrument for representing these different models and relies on the instrument to explain the rationale of the astronomical tables. The second text is the De armilis of Profatius Judaeus. This text also describes an instrument for displaying the geometrical planetary models. ${ }^{18}$ It is 12 pages (fols $35^{\mathrm{r}}-40^{\mathrm{v}}$ ) long, with the same kind of combination of text, diagrams, and tables as the previous work. The following two works are much smaller units. De horologio is 3 pages (fols $41^{r}-42^{r}$ )

17 Benjamin and Toomer 1971, 83.

18 Poulle 1980, 66. 
long, with text and diagrams. ${ }^{19}$ It deals with the topic of water clocks. Moreover, a small text on proportions with the incipit Incipit arithmetica de rerum ac numerorum proprietationibus takes up 6 pages of text (fols $\left.42^{\mathrm{v}}-45^{\mathrm{r}}\right){ }^{20}$ The last 7 pages of the quire and booklet are left blank so that the choice of this work, near the end of the booklet, is probably not explained by an optimisation of page space: Heingarter did not select small works to fill empty pages near the end of a quire.

The second booklet (quires 6 to 9) has a similar organisation of large and small works. Two small, unidentified works dealing with proportions take up 3 pages. The first work, with the incipit Si vis scire quantitatem cuiuslibet linee, occupies fol. $49^{\mathrm{r}}$. The second, with the incipit Notandum quod habendo aliquid de modo proferendi, occupies fols $92^{\mathrm{v}}-93^{\mathrm{r}}$. The last 11 pages of the booklet are left blank (almost half of quire 9). Two large works fill the remaining 86 pages. Ps.-Messahala's De astrolabio takes up 31 pages (fols 49 ${ }^{\mathrm{r}}-64^{\mathrm{r}}$ ), with a combination of texts, tables, and diagrams. Like the works found in the first booklet, this one also treats the topic of an instrument. However, the astrolabe is an instrument devoted to the astronomy of daily motion and to spherical astronomy. Interestingly, an autonomous series of diagrams extracted from the Theorica planetarum Gerardi is inserted at the end of this treatise. The second large work of this booklet takes up 51 pages, 43 of which are tables and 8 are text. This work is a German adaptation of the Six Wings by Immanuel Bonfils, a midfourteenth-century treatise on eclipse computation that was originally written in Hebrew. ${ }^{21}$ No other copies of this version have been identified.

The third booklet coincides with quire 10 and with the second half of the codex, where Heingarter's intervention is mainly that of a reader and compiler and less that of a copyist. This quire's central work (fols 101 $-111^{\mathrm{v}}$ ) consists of John of Saxony's canons to the Parisian Alfonsine tables with the incipit Tempus est mensura motus. This work takes up only 22 pages, all text. The work expounds different procedures for computing planetary positions in longitude and syzygies with the Parisian Alfonsine Tables. It is without any doubt the most copied work of the whole Alfonsine tradition with hundreds of extent copies. Heingarter devoted special attention to the topic of syzygies, which he annotat-

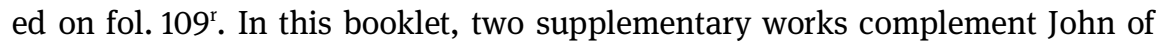
Saxony's canons. One is an ascension table for Toledo $\left(45^{\circ}\right)$ on fols $112^{r}-113^{v}$. This table is extracted from a larger set known as the Toledan Tables..$^{22}$ The last

19 Thorndike and Kibre1963, 949, incipit: Notandum pro horalogiis in trunco faciendis.

20 Thorndike and Kibre1963, 1437.

21 Solon 1971, 1-20; Lévy 2003, 283-304; Goldstein 2007; Goldstein and Chabás 2017, 71-108.

22 Pedersen 2002, 1066-1070. 
work of this booklet is 3 pages long, all text. This work, with the incipit Ad intelligendum tabulas astronomie necessario opportet scire quid sit, defines different concepts of mathematical astronomy that are necessary to work with the table. ${ }^{23}$ Here the fragment or small work provides a basic vocabulary helpful for reading the core and larger work of the booklet. The small definitional text is cut into two sections. A first part is found on fol. $99^{r-v}$, and a second part is found on fol. $114^{\mathrm{r}}$.

The fourth booklet (quires 11 to 13) comprises 6 works. The first extends to 38 pages (fols $115^{\mathrm{r}}-127^{\mathrm{r}}, 128^{\mathrm{r}}-134^{\mathrm{v}}$ ) and contains the Parisian Alfonsine Tables. ${ }^{24}$ John of Saxony redacted Tempus est mensura motus for this set of tables. This set of tables, computed on the longitude of Toledo, provides the elements for computing planetary longitude. Heingarter added, in marginalia to these tables, two sets of radices for Paris and Vienne (France). These additions make the tables directly useful for two meridians where Heingarter is known to have worked (fols. $117^{\mathrm{v}}-123^{\mathrm{r}}$ ). Apart from these marginalia, many other smaller works supplement the Parisian Alfonsine Tables in this booklet. They are mostly taken from the larger corpus of the Toledan Tables. Heingarter copied in his own hand a planetary latitude table on fol. $127^{\mathrm{v}}$. Four other fragments or small works, dealing, respectively, with planetary stations, planetary aspects, Solar and lunar velocities, and finally spherical astronomy fill the last 20 pages of the booklet (including one final blank page). In this booklet the fragments or short works complement the large, core work of the booklet by addressing topics that are not addressed by the Parisian Alfonsine Tables.

Heingarter copied the fifth booklet himself (quire 14). It contains only one work (fols $145^{\mathrm{r}}-152^{\mathrm{r}}$ ). The Planetary latitude tables of Oxford fill 10 pages. ${ }^{25}$ They address the issue of planetary latitude in a fundamentally different way than the small tables copied on fol. $127^{\mathrm{v}}$ in the preceding booklet. The last 5 pages of the booklet are left blank.

The sixth booklet (quires 15-16) contains two works linked to John of Lignères. The first (fols $155^{\mathrm{r}}-171^{\mathrm{v}}$ ) is 34 pages of tables. It is known in the literature as John of Lignères's Tables of $1322 .{ }^{26}$ It is a set of astronomical tables compiled by John of Lignères in Paris, dealing mainly with spherical astronomy and eclipse computations. Many of those tables are directly linked to the Toledan tradition, but a few of them also relate to the Alfonsine tradition. Part of the

23 Thorndike and Kibre 1963, 48.

24 Chabás 2019, 237-276.

25 Chabás 2019, 227-236.

26 Chabás 2019, 175-199. 
content of this set is redundant, for instance, with respect to planetary latitude, and to what is found in the preceding booklet. This set of tables closes the tabular section of the codex that was engaged in booklet four. After four blank pages, the second work of this booklet is found (fols $174^{\mathrm{r}}-180^{\mathrm{v}}$ ), occupying the remaining 14 pages, all text. It is the Priores astrologi by John of Lignères, a text probably written in connection with the Tables of 1322 and addressing planetary longitude, latitude, and eclipse computation. ${ }^{27}$ Heingarter devoted close attention to the topic of planetary latitude in this text. This is evident from the way he rubricated and punctuated the portion of the Lignère's work devoted to this topic (fol. 178 ${ }^{\mathrm{r}}$ )

The last booklet of the manuscript (quire 17), mostly copied by Heingarter, begins with two short works. The first, which occupies only a part of fol. $181^{\mathrm{r}}$, may be a fragment on eclipse by John of Lignères. ${ }^{28}$ The following one (fol. $181^{\mathrm{r}-\mathrm{v}}$ ) includes text and diagrams. It discusses theoretical issues that have to do with planetary motions and eclipses, drawing on al-Farghani and Ptolemy. The last work of the manuscript, with the incipit Arabes maxime secudum motum lune (fols $182^{\mathrm{r}}-193^{\mathrm{v}}$ ), includes texts, diagrams, and small tables on 24 pages. ${ }^{29}$ It addresses in a theoretical way many aspects of mathematical astronomy, from trigonometry to eclipses, with reference to Ptolemy, Euclid, al-Farghani, the canons to the Toledan Tables, and the Parisian Alfonsine tables.

Core works and short works interact in two mains ways in the manuscript. In some cases, fragments and short works complement the core works by proposing alternatives to astronomical topics that have already been addressed or by covering entirely different topics. In other cases, fragments and short works provide foundational information, such as definitions or basic arithmetical techniques. Independent of this distinction between core works and short works, a different distinction between works appears. It bears on the way they rely on different combinations of graphical expression. Some works are text only: these are in general procedural texts expounding the use of astronomical tables in computing different kinds of astronomical quantities. Other works consist only of tables. They collect table sets as described above. Finally, a third class of works combines texts, diagrams, and small tables. They address instruments and contain theoretical reflection on planetary models and computation procedures. These works are placed at the start and at the end of the codex, while works that consist only of tables or text are the core of the codex. These

27 Saby 1987, 173-277.

28 Pedersen 2002, 535.

29 Thorndike and Kibre 1963, 124. 
more theoretical works provide meaning and guidance to the long and tedious astronomical computations supported by the manuscript.

Almost each of the main areas of astronomical computation (longitude, latitude, eclipse, spherical astronomy) is addressed many times and through different means with the three types of works distinguished above (in some cases even in a single booklet). Thus, the computation practices under scrutiny here are not only about the consideration of sets of mathematical relations between astronomical quantities, they are about multiple paths among these relations and multiple ways to group and consider them. The result is a thick and flexible computational practice.

\section{Conclusion}

This survey through the different works of the manuscript, their distribution in the material units of the codex, and their relation to the different graphical expressions teaches many things with respect to the features of toolbox manuscripts and the type of computation practices they support.

From this case study, this toolbox manuscript appears to have a complex material organisation reflecting of the life that the different booklets and quires had before binding. The process of production is opportunistic and strongly linked to a given individual who copies, selects, and organises different elements. This individual interacts differently with the different parts of the manuscript, and the visual organisation of the codex reflects this production process. The hand of the individual responsible for the codex is found throughout, but other hands are found as well. There is no uniformity in ruling, decoration, rubrication, or punctuation marks. Finally, the intellectual organisation of the codex establishes a set of large, core works that are placed in dialogue with many shorter or fragmentary works.

The long and personal production process of the manuscript, certainly at least partly concomitant with Heingarter's student years in Paris, reflects the training required by the computation practices that the codex attests. The different works found in the manuscript are, in the majority of cases, wellestablished elements in a corpus of mathematical astronomy shared in university and courtly milieus, where Heingarter evolved. By selecting his own set of tools, Heingarter inscribed himself in this tradition. Thus, to some extent this computation practice is also a social practice that is evaluated by peers with respect to the way it is inscribed in a tradition. Finally, the complexity and reflexivity of this computation practice appeared from two distinct features. First, 
on the visual level, diagrams and grids of numerical tables display different sets of relations between astronomical quantities. Second, the importance of redundancy and variation in how works of different types are assembled indicates that the exploration of multiple computational paths among astronomical quantities is an important value for historical actors.

\section{Acknowledgements}

I thank Camille Bui, Eleonora Andriani, Samuel Gessner and Nicholaus Jacobson for the very fruitful collective analysis of this manuscript we have done together in 2019-2020. I am also grateful to the referees for their helpful comments and suggestions on earlier draft of the work. The efficient and professional contribution of the language editor and copy-editor deserve also mention. All remaining inaccuracies are mine. Research presented in this article was supported by the ERC project ALFA (CoG 723085, PI Matthieu Husson).

\section{References}

Benjamin, Francis S. and Gerald J Toomer (1971), Campanus of Novara and Medieval Planetary Theory (Publications in Medieval Science, 16), Madison: The University of Wisconsin Press.

Chabás, José (2019), Computational Astronomy in the Middle Ages: Sets of Astronomical Tables in Latin (Estudios sobre la Ciencia, 72), Madrid: Consejo Superior de Investigaciones Científicas.

Goldstein, Bernard R. (2007), 'Bonfils, Immanuel Ben Jacob', in Michael Berenbaum and Fred Skolnik (eds), Encyclopaedia Judaica, vol. 62, Detroit: Macmillan Reference USA.

Goldstein, Bernard R. and José Chabás (2017), 'Analysis of the Astronomical Tables for 1340 Compiled by Immanuel Ben Jacob Bonfils', Archive for History of Exact Sciences, 71: 71108.

Husson, Matthieu (2019) 'Mathematical Astronomy and the Production of Multiple Texts Manuscripts in Late Medieval Europe: a Comparison of BnF lat. 7197 and BnF lat. 7432', in Alessandro Bausi, Michael Friedrich and Marilena Maniaci (eds), The Emergence of Multiple-Text Manuscripts (Studies in Manuscript Cultures, 17), Berlin: De Gruyter, 247-274.

Husson, Matthieu and Marie-Madeleine Saby (2019), 'Le manuscrit Erfurt F. 377 et l'astronomie Alphonsine parisienne’, Micrologus, 27: 205-234.

Jacquart, Danielle (1979), Supplément [au] Dictionnaire biographique des médecins en France au Moyen Age [d'Ernest Wickersheimer], Geneva: Droz.

Kremer, Richard L. (2021), 'Exploring a late Fifteenth-Century Astrologer’s Toolbox: British Library Add Ms 34603', in Richard L. Kremer, Matthieu Husson and José Chabás (eds), Alfonsine Astronomy: The Written Record, Turnhout: Brepols, forthcoming.

Lévy, Tony (2003), 'Immanuel Bonfils (XIVe s.): Fractions, décimales, puissances de 10 et opérations arithmétiques', Centaurus, 45: 283-304. 
Nicoud, Marilyn (2007), Les régimes de santé au Moyen Âge: Naissance et diffusion d'une écriture médicale en Italie et en France (XIIIe-XVe siècle), Rome: Publications de l'École française de Rome, <doi.org/10.4000/books.efr.1448>.

Pedersen, F. S. (2002), The Toledan Tables: A Review of the Manuscripts and the Textual Versions with an Edition (Historisk-filosofiske Skrifter, 24), Copenhagen: Det Kongelige Danske Videnskabernes Selskab.

Poulle, Emmanuel (1980), Les instruments de la théorie des planètes selon Ptolémée: équatoires et horlogerie planétaire du XIIle auXVIe siècle, Geneva: Droz.

Saby, Marie-Madeleine (1987), Les canons de Jean de Lignères sur les tables astronomiques de 1321, PhD thesis, Paris, École Nationale des Chartes.

Solon, Peter (1971), 'The Six Wings of Immanuel Bonfils and Michael Chrysokokkes', Centaurus, 15: 1-20.

Thorndike, Lynn (1934), A History of Magic and Experimental Science, vol. 4 (History of Science Society Publication, New Series, 4), New York: Columbia University Press.

Thorndike, Lynn and Kibre, Pearl (1963), A Catalogue of Incipits of Mediaeval Scientific Writings in Latin (The Mediaeval Academy of America Publication, 29), London: William Clowes and Sons. 


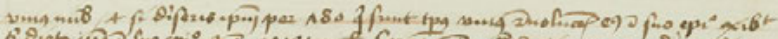

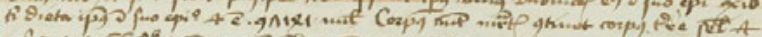

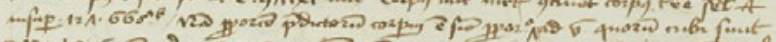

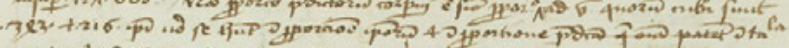

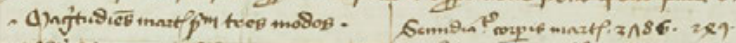

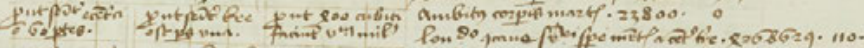

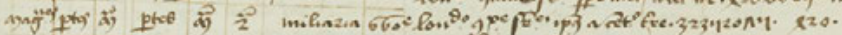

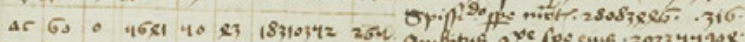

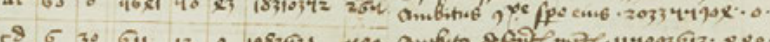

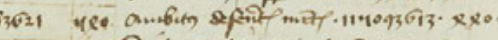

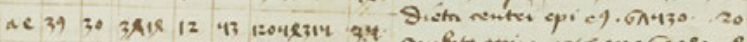

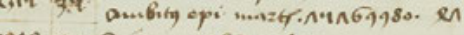

$96 \quad 13 \quad 30 \quad 1050 \quad 31 \times 3 \quad 1632630 \quad 384$

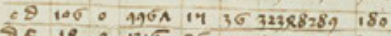

If 12.1316 .2640 sanzsi4 340

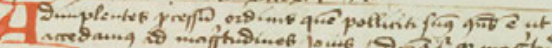

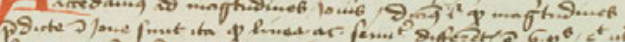

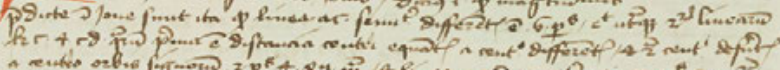

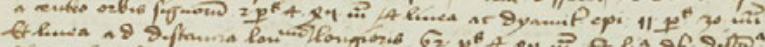

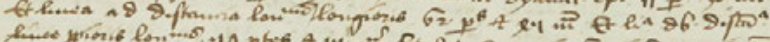

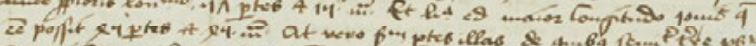

a......

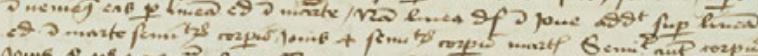

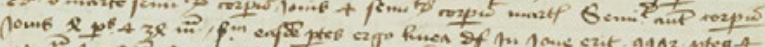

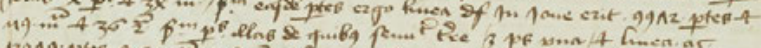

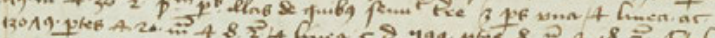

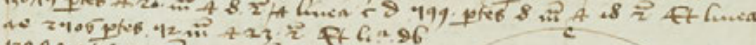

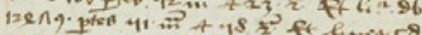

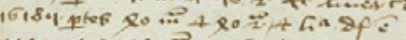

(29)

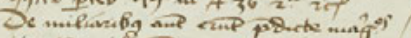

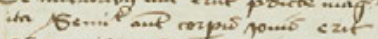

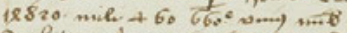

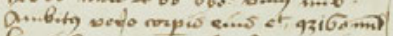

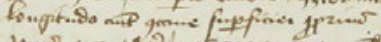

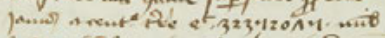

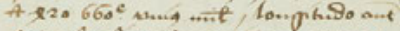

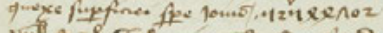

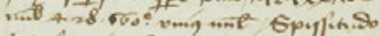

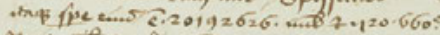

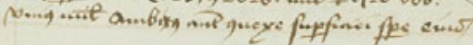

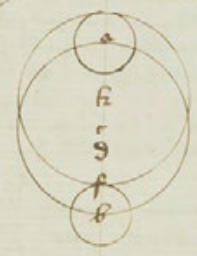

Fig. 1: The layout of texts, tables and diagrams (Paris, BnF, lat. 7295A, fol. 30'). () Bibliothèque nationale de France. 


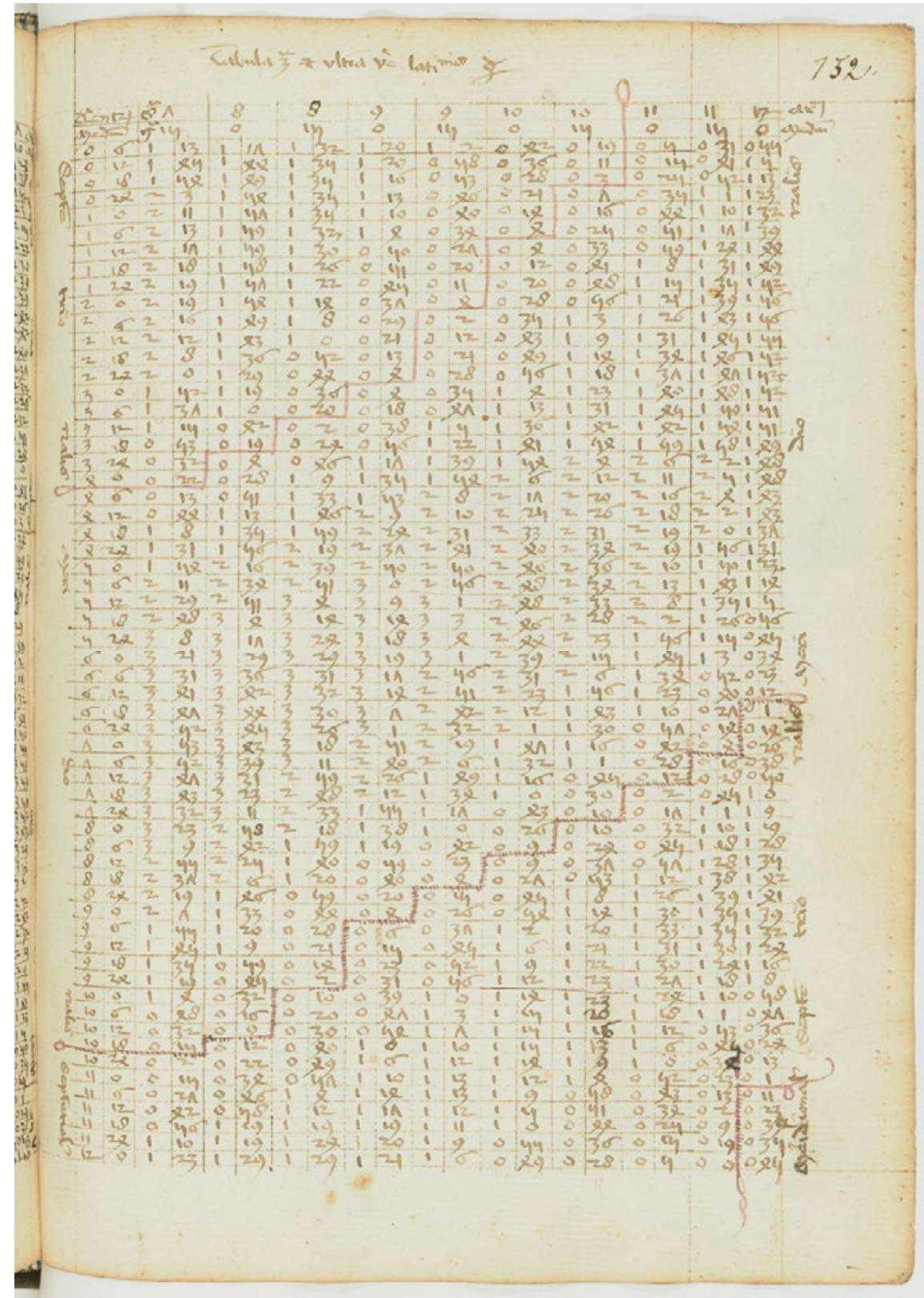

Fig. 3: Third grid for the true latitude of Mercury (Paris, BnF, lat. 7295A, fol. 152'). (c) Bibliothèque nationale de France. 


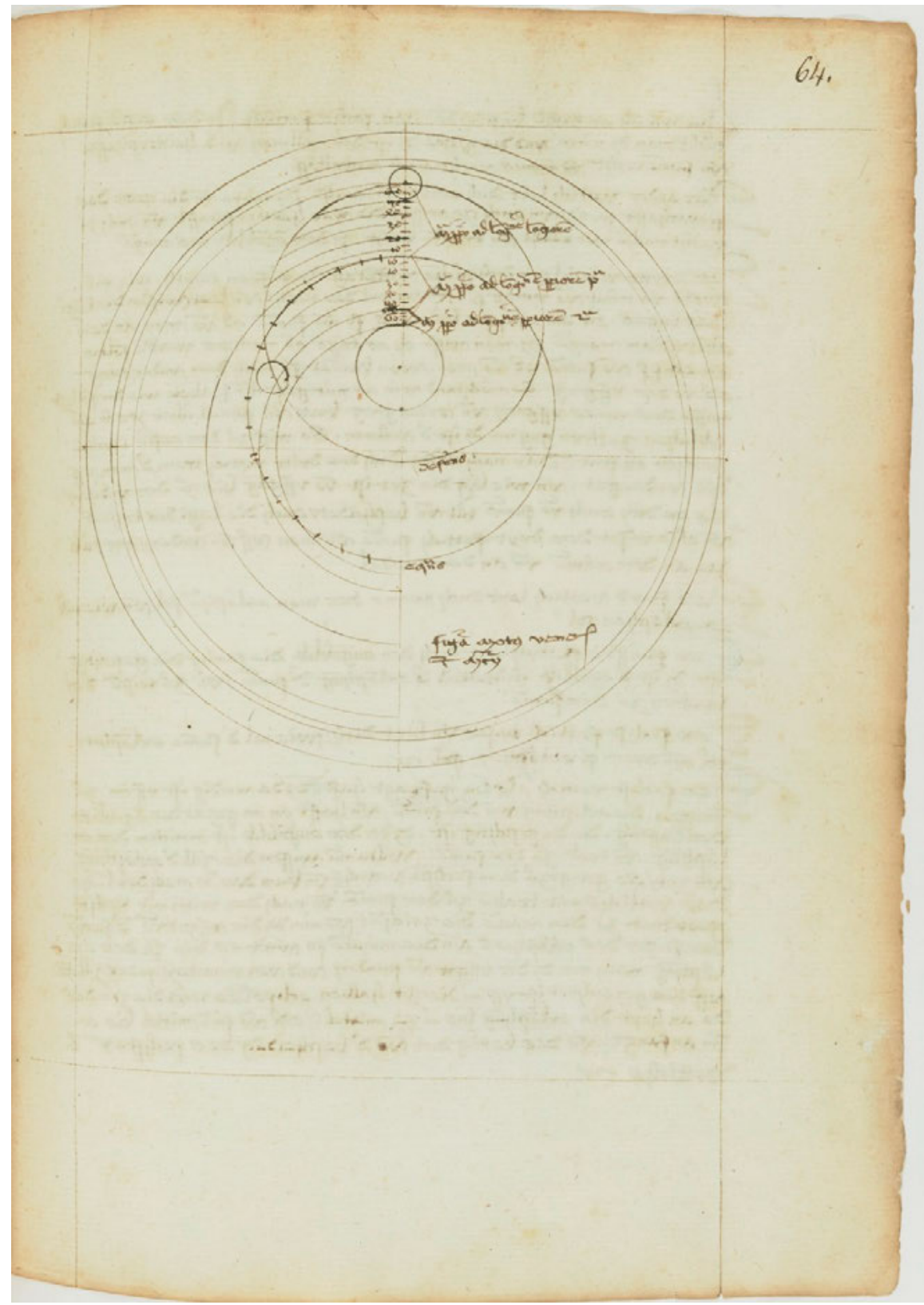

Fig. 4: Figure for the motion of Venus and Mercury (Paris, BnF, lat. 7295A, fol. 64'). ( Bibliothèque nationale de France. 